\title{
Contextualization of cost-effectiveness evidence from literature for 382 health interventions for the Ethiopian essential health services package revision
}

Alemayehu Hailu ${ }^{1,2^{*}}$ (D), Getachew Teshome Eregata ${ }^{1,2}$, Amanuel Yigezu ${ }^{3}$, Melanie Y. Bertram ${ }^{4}$, Kjell Arne Johansson ${ }^{1}$ and Ole F. Norheim ${ }^{1,5}$

\begin{abstract}
Background: Cost-effectiveness of interventions was a criterion decided to guide priority setting in the latest revision of Ethiopia's essential health services package (EHSP) in 2019. However, conducting an economic evaluation study for a broad set of health interventions simultaneously is challenging in terms of cost, timeliness, input data demanded, and analytic competency. Therefore, this study aimed to synthesize and contextualize cost-effectiveness evidence for the Ethiopian EHSP interventions from the literature.
\end{abstract}

Methods: The evidence synthesis was conducted in five key steps: search, screen, evaluate, extract, and contextualize. We searched MEDLINE and EMBASE research databases for peer-reviewed published articles to identify average cost-effectiveness ratios (ACERs). Only studies reporting cost per disability-adjusted life year (DALY), quality-adjusted life year (QALY), or life years gained (LYG) were included. All the articles were evaluated using the Drummond checklist for quality, and those with a score of at least 7 out of 10 were included. Information on cost, effectiveness, and ACER was extracted. All the ACERs were converted into 2019 US dollars using appropriate exchange rates and the GDP deflator.

Results: In this study, we synthesized ACERs for 382 interventions from seven major program areas, ranging from US\$3 per DALY averted (for the provision of hepatitis B vaccination at birth) to US\$242,880 per DALY averted (for latestage liver cancer treatment). Overall, $56 \%$ of the interventions have an ACER of less than US\$1000 per DALY, and $80 \%$ of the interventions have an ACER of less than US\$10,000 per DALY.

Conclusion: We conclude that it is possible to identify relevant economic evaluations using evidence from the literature, even if transferability remains a challenge. The present study identified several cost-effective candidate interventions that could, if scaled up, substantially reduce Ethiopia's disease burden.

Keywords: Cost-effectiveness analysis, Priorities setting, Essential health services package, Ethiopia

*Correspondence: Alemayehu.hailu@uib.no

${ }^{1}$ Bergen Centre for Ethics and Priority Setting, Department of Global Public Health and Primary Care, University of Bergen, Bergen, Norway

Full list of author information is available at the end of the article

\section{Introduction}

Because of the rapid expansion of new technologies and health interventions, priority setting-implicitly or explicitly-is inevitable. To rapidly and efficiently progress towards universal health coverage (UHC), what policy makers can deliberately choose to do is carefully original author(s) and the source, provide a link to the Creative Commons licence, and indicate if changes were made. The images or other third party material in this article are included in the article's Creative Commons licence, unless indicated otherwise in a credit line to the material. If material is not included in the article's Creative Commons licence and your intended use is not permitted by statutory regulation or exceeds the permitted use, you will need to obtain permission directly from the copyright holder. To view a copy of this licence, visit http://creativecommons.org/licenses/by/4.0/. The Creative Commons Public Domain Dedication waiver (http://creativeco mmons.org/publicdomain/zero/1.0/) applies to the data made available in this article, unless otherwise stated in a credit line to the data. 
define an optimal national essential health services package (EHSP) that can be delivered within the expected budget envelope [1-5]. Cognizant of this, the Ethiopian government defined its EHSP in 2019, and cost effectiveness was selected as one of the criteria for prioritizing the health interventions in the revision process, together with six other criteria [6].

Ranking interventions by their cost-effectiveness ratio can help prioritize interventions that provide the highest health impact at a relatively lower cost [7]. Many highincome countries and some low- and middle-income countries (LMICs) explicitly use cost-effectiveness analysis (CEA) in policy decisions about the introduction of new interventions into the health system $[1,8$, 9]. For example, in Thailand's' health technology assessment (HTA) process, CEA is the primary consideration in priority decision of this kind [10]. However, conducting primary health economic evaluations in each of these settings of a wide range of health interventions simultaneously is challenging due to cost, time, scarcity of input data, and computational capacity constraints.

An international effort of donors and academia in support of economic evaluation has produced substantial cost-effectiveness evidence over the past two decades. The World Health Organization (WHO), the Center for the Evaluation of Value and Risk in Health at Tufts Medical Center, and Disease Control Priorities (DCP) have produced cost-effectiveness evidence for priority-setting purposes in LMICs. The Tuft CEA registry is a comprehensive, publicly available database that contains 6,907 cost per quality-adjusted life year (QALY) and 698 cost per disability-adjusted life year (DALY) studies published through 2018 [11]. The DCP-3 synthesized cost-effectiveness ratios for 93 interventions from diverse program areas in 2016 [12]. WHO has produced a series of reports on the cost effectiveness of health interventions targeted in the Millennium Development Goals (i.e., tuberculosis [TB], malaria, HIV/AIDS, and maternal, neonatal, and child health) [13-16]. However, this evidence is mostly at the global or regional level and encompasses limited program areas. Country-specific synthesis and contextualization of cost-effectiveness evidence were therefore necessary for revising the latest Ethiopian EHSP. This paper aimed to synthesize and contextualize the costeffectiveness evidence for the Ethiopian EHSP interventions from the literature.

\section{Methods}

\section{Study context}

This study was conducted in Ethiopia in 2019 as part of the revision of the Ethiopian EHSP (Box 1) [17]. Ethiopia has a substantial disease burden, with an average life expectancy of 65.5 years $[18,19]$. Communicable, maternal, neonatal, and nutritional diseases (CMNNDs) represent the highest disease burden, accounting for $58 \%$ of DALY loss in 2017, while noncommunicable diseases (NCDs) accounted for $34 \%$ of the disease burden. About $8 \%$ of the DALYs were from emergencies and injuries [19]. Furthermore, Ethiopia is a low-income country with a per capita gross domestic product (GDP) of US\$953 in 2019 [20]. The per capita health expenditure in Ethiopia in $2016 / 17$ was US\$33 [21].

\section{Identification of relevant health interventions}

The detailed steps used to select the interventions are presented elsewhere [6, 22]. From the total of 1018 unique interventions that were considered in the Ethiopian EHSP, the cost-effectiveness ratio was calculated using primarily the WHO-CHOICE GCEA approach for 144 interventions [23]. Additionally, we collected costeffectiveness evidence for 771 interventions from the literature, excluding 64 multisector nutrition interventions and 39 emergency and critical care interventions [22]. A detailed breakdown of the number of interventions by evidence synthesis method is presented in Table 1.

\section{Evidence synthesis}

We adopted an evidence synthesis strategy developed by the Tuft CEA registry [11]. The cost-effectiveness evidence synthesis was conducted in five key steps: search, screen, evaluate, extract, and contextualize (Fig. 1). The first, second, and third authors (AH, AY, and GTE) conducted all five steps of the evidence synthesis process from January-August 2019.

\section{Search}

To identify cost-effectiveness studies on a given intervention from the EHSP list, we searched for peer-reviewed and published articles in MEDLINE and EMBASE research databases. These databases are the most used databases for medicine and healthcare evidence synthesis. The search was conducted intervention by intervention using a combination of keywords indicating the intervention name, the program area, and the type of study (i.e., cost effectiveness, cost utility, economic evaluation). For example, for the intervention entitled "Detection of uncomplicated malaria using rapid diagnostic test and treatment with artemether-lumefantrine," an extensive literature search was conducted using keywords such as "malaria," "malaria treatment," "artemether-lumefantrine," "falciparum," "vivax," "rapid diagnosis testing," "Plasmodium," "cost-effectiveness,".

\section{Screen}

In this step, we conducted a preliminary assessment and screening of articles based on the inclusion and exclusion 


\section{Box 1 Ethiopian EHSP}

\section{What is the EHSP, and why was the revision needed?}

The government of Ethiopia is committed to achieving universal health coverage. Universal health coverage means that every person-no matter who they are, where they live, or how much money they have — should be able to access quality health services without financial hardship.

However, it is impossible to progress toward universal health coverage without clearly identifying the most pressing health problems and what interventions are appropriate to address those health problems efficiently and equitably.

Therefore, defining the essential health services package is the primary step to use the available resources to prioritize the most critical interventions based on cost, equity, financial risk protection, and public interest (community concern) justifications.

An EHSP can be defined as the package of services that the government provides or is aspiring to provide to its citizens equitably.

The Ethiopian EHSP identified the most pressing health challenges and interventions deemed appropriate, affordable, and equitable to address health problems.

\section{Goal of the EHSP}

To provide access to quality health services for all Ethiopians with full financial risk protection regardless of age, ability to pay, economic status, and residence.

\section{Objectives of the EHSP}

To reduce the high burden of disease in Ethiopia by making available affordable, high-priority interventions.

To protect the population against catastrophic and impoverishing health expenditures and provide full financial risk protection.

To increase equitable access to health services and interventions.

To increase the efficiency of the health system.

To increase public participation and transparency in decision-making in the health sector.

\section{The revision process}

The revision process was conducted from May 2018-November 2019.

As recommended by the World Health Organization for designing health benefits packages, the revision was conducted using the best available evidence (data), was based on extensive consultation with all stakeholders (dialogue), and was conducted through an open, transparent, and democratic decision-making process (decision).

Several consultations have been held with public representatives and professional association experts actively participating in the revision process. Interventions were compared based on seven criteria: disease burden, cost effectiveness, equity, financial risk protection, budget impact, public acceptability, and political acceptability.

Table 1 Number of essential health service package interventions and cost-effectiveness evidence synthesis approaches by program area

\begin{tabular}{lclll}
\hline Major program areas & Total & WHO-CHOICE & Searched & Contextualized \\
\hline RMNCH & 333 & 51 & 282 & 121 \\
Noncommunicable diseases & 218 & 74 & 144 & 93 \\
Surgical care & 181 & 0 & 0 & 90 \\
Multisectoral nutrition interventions* & 64 & 18 & - & - \\
Major communicable diseases & 62 & 1 & 56 & 36 \\
Health education and BCC & 57 & 0 & - & 13 \\
Emergency and critical care* & 39 & 0 & 35 & - \\
Neglected tropical diseases (NTDs) & 35 & 0 & 29 & 12 \\
Hygiene \& environment health (H\&EH) & 29 & 144 & 771 & 17 \\
Overall & 1018 & & 382 \\
\hline
\end{tabular}

Searched $=$ CEA evidence was sought from the literature; contextualized $=$ CEA evidence was found and contextualized

$B C C$ Behavioral change communication

*For multisectoral nutrition interventions and emergency and critical care interventions, we classified interventions as very cost effective, cost effective, and not cost effective based on local expert judgment

criteria. First, only original studies published in the English language from 1990 through 2019 were included. Second, only economic evaluation studies reporting cost per DALY, QALY, or life years gained (LYG) were included. Priority was given to those studies that reported cost per DALY or QALY, but 28 studies reporting cost per LYG were included. All other articles using a natural unit of measurement (e.g., case identified, cured, 


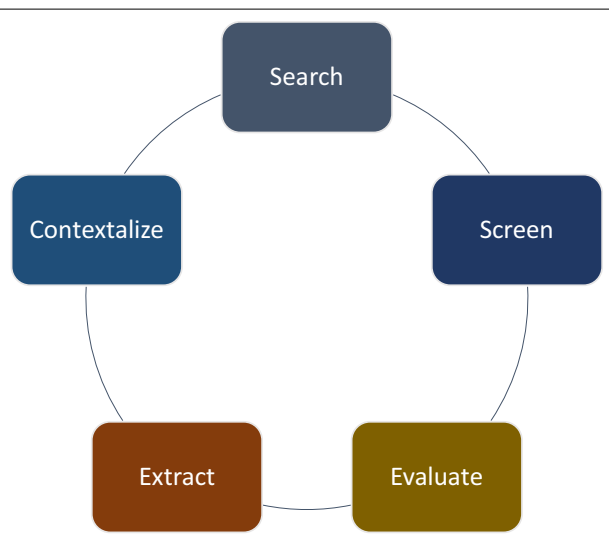

Fig. 1 Schematic diagram for the evidence synthesis process (Source: Produced by the authors for this publication)

or treated) were excluded. Partial economic evaluation studies (e.g., cost of illness) and full economic evaluations using a cost-benefit analysis study were also excluded. Third, we only included studies that compared the intervention with the "doing nothing/null scenario" and studied reporting average cost-effectiveness ratios (ACERs). Fourth, only studies conducted from the health service provider's perspective were included.

\section{Evaluate}

The transferability of evidence was thoroughly checked during the evaluation phase by examining the study's context and its quality. In terms of the study context, studies from low-income settings, particularly from subSaharan Africa, were included in the first place. If no study was found in low-income settings, studies from middle- and high-income settings were also included as an alternative.

The final appraisal of the transferability and quality of studies was done using the Drummond checklist [24]. The Drummond checklist has 10 domains, and we scored each domain as 0 or $1(0=$ not fulfilled and $1=$ fulfilled $)$ with an aggregate score out of 10 points. Only studies with a score of at least 7 were included (Additional file 1). When multiple studies were found on the same interventions, recent studies and those with a higher quality score were included. For the purpose of quality control, all the articles were double checked by two reviewers. All the studies were exported to EndNote reference managing software to avoid duplication. The full list of studies with the score is provided in Additional file 2.

\section{Extract}

Once the high-quality cost-effectiveness studies were identified, the extraction of the information from the articles was done using a predefined data extraction format
(Additional file 3). The data extraction format contains the country of the study, base year, currency, type of ratio reported (i.e., ICER, ACER, or both), unit cost, total cost, and discounts. We extracted the following information from each of the studies: ACER, country, base year of analysis, currency, units of health outcome measurement (i.e., DALY, QALY, or LYG), unit cost per intervention, total cost, and total DALY/QALY/LYG. We also extracted information about whether or not discounting was done and, if done, what percentage of discounting for cost and health outcome was applied.

\section{Contextualize}

Contextualization of the information was done by adjusting the currency and time differences across the individual studies. First, an appropriate exchange rate was used to convert the currencies from local currency units into US\$ [25]. Then, to convert the ACERs reported in various years into 2019 US\$, we employed the US GDP deflator. Finally, all the ACERS are reported in 2019 US\$. Studies from a country where context varied too much from the Ethiopian setting were excluded at this stage.

\section{Data analysis}

Descriptive analysis was done to summarize the findings for each of the interventions into program areas. We initially generated the median ACER with interquartile range (IQR) across the program. The results are presented in tabular, bar graph, and dot-plot forms. We also present the ACERs in the form of a league table. The data were analyzed using Stata version 16 and Microsoft Excel.

\section{Results}

In total, ACERs for 382 interventions were synthesized from seven major program areas. The ACERs were collected from 268 studies. Many of the included studies were conducted in the period 2010-2014 (38\%), with fewer in the period 2015-2018. The majority (57\%) of the studies were from LMICs in Africa or other LMICs outside of Africa (e.g., Pakistan, China, Thailand). We found an ACER for 13 interventions from study sources in Ethiopia. In comparison, $43 \%$ were from high-income countries. Most (32\%) of the interventions are from the reproductive maternal neonatal and child health (RMNCH), followed by NCDs (24\%), surgical care (23\%), communicable diseases (CD) (9\%), and hygiene and environmental health interventions $(5 \%)$.

The majority (68\%) of the studies included were scored 10 out of 10 based on the Drummond checklist. Nearly half $(46 \%)$ of the studies employed DALY as a health outcome measure while the other $45 \%$ employed QALY and 
7\% employed LYG. We present the full list of ACERs for interventions by program area and sub-program area in the Additional file 3. In Table 2 below, we present the key findings for major program areas.

An overview of the ACERs for interventions by major program area is presented in Fig. 2. The Y-axis represents ACER in the log scale. A dot represents an ACER for a single intervention. The horizontal gray line represents ACER $=$ US $\$ 1,000$ per DALY. Overall, slightly more than half of the interventions had ACERs of less than US $\$ 1,000(n=216 ; 56 \%)$. However, the majority of NTDs $(\mathrm{n}=11 ; 92 \%)$, hygiene and environmental health $(\mathrm{n}=17$; $81 \%)$, and communicable disease $(n=27 ; 75 \%)$ had ACERs lower than US $\$ 1,000$ while less than half $(n=37$; $40 \%$ ) of NCD interventions had ACERs below US $\$ 1,000$.

In general, we found ACERs ranging from the lowest of US\$3 per DALY averted (for the provision of hepatitis $B$ vaccination at birth) to the highest of US $\$ 242,880$ per

Table 2 Summary of contextualized studies

\begin{tabular}{|c|c|c|}
\hline Characteristics & Number & Percentage (\%) \\
\hline \multicolumn{3}{|l|}{ Study periods $(n=382)$} \\
\hline 1990-1994 & 10 & $3 \%$ \\
\hline 1995-1999 & 15 & $4 \%$ \\
\hline $2000-2004$ & 71 & $19 \%$ \\
\hline 2005-2009 & 98 & $26 \%$ \\
\hline 2010-2014 & 144 & $38 \%$ \\
\hline 2015-2018 & 44 & $12 \%$ \\
\hline \multicolumn{3}{|l|}{ Study regions $(n=382)$} \\
\hline LMIC in Africa & 173 & $45 \%$ \\
\hline LMIC outside Africa & 44 & $12 \%$ \\
\hline United States of America & 73 & $19 \%$ \\
\hline United Kingdom & 32 & $8 \%$ \\
\hline Other high-income countries & 60 & $16 \%$ \\
\hline \multicolumn{3}{|c|}{ Health outcome measures $(n=382)$} \\
\hline DALY & 174 & $46 \%$ \\
\hline QALY & 180 & $47 \%$ \\
\hline LYG & 28 & $7 \%$ \\
\hline \multicolumn{3}{|l|}{ Major program area $(n=382)$} \\
\hline $\mathrm{RMNCH}$ & 121 & $32 \%$ \\
\hline Surgical care & 90 & $23 \%$ \\
\hline NCD & 93 & $24 \%$ \\
\hline$C D$ & 36 & $9 \%$ \\
\hline $\mathrm{H} \& \mathrm{EH}$ & 21 & $5 \%$ \\
\hline NTD & 12 & $3 \%$ \\
\hline $\mathrm{HE} \& \mathrm{BCC}$ & 13 & $3 \%$ \\
\hline \multicolumn{3}{|c|}{ Quality score of the studies $(n=268)$} \\
\hline Score $10 / 10$ & 183 & $68 \%$ \\
\hline Score $9 / 10$ & 56 & $21 \%$ \\
\hline Score $8 / 10$ & 26 & $10 \%$ \\
\hline Score $7 / 10$ & 3 & $1 \%$ \\
\hline
\end{tabular}

DALY averted (for late-stage liver cancer treatment). Figure 3 presents an overview of the 20 most cost-effective interventions, and Fig. 4 shows the 20 least cost-effective interventions based on the ACER ranking. In both the top 20 and bottom 20 interventions, we found that many of the major program areas were represented. We present the full list of ACERs for interventions by program area and sub-program area in the Additional file 3. In Table 3, we present the range, median, and IQR of ACERs by major program area. The overall median of the ACERs was 677 (IQR: 87-4761).

\section{Discussion}

We contextualized cost-effectiveness evidence for a relatively comprehensive list of interventions to the Ethiopian context for the revision of the country's EHSP. In this study, we found that, while most CDs, NTDs, and hygiene and environmental health interventions had relatively low ACERs, more than half of the NCD interventions had an ACER higher than US $\$ 1,000$ per DALY. Compared with the need for the purpose of EHSP revision, the amount of cost-effectiveness evidence available in the literature so far is limited in all program areas. It is critically scarce in some programs, such as multisectoral interventions, emergency and critical care, and surgical care. These findings on the extent of the available evidence and the variation in ACERs across program areas or disease categories are similar in many ways to the findings of 'Tufts' Global Health Cost-Effectiveness Analysis Registry [26].

The availability of cost-effectiveness evidence customized to the epidemiological and socioeconomic context of the country is a central element in the proper revision of the EHSP. However, our findings show that only a few cost-effectiveness studies exist for a specific country in Africa. For example, we found an ACER for only 13 interventions in studies from Ethiopia, eight from Kenya, seven from Malawi, six from Tanzania, five from Uganda, and four from Zambia. A recent analysis of Tufts Medical Center's CEA registry indicates the same [27]. Furthermore, as was agreed upon in preparing the roadmap for revising the Ethiopian EHSP, we included studies conducted from a health systems perspective and studies reporting ACERs [6]. This further limited the number of studies available per country. Therefore, to generate more transferable cost-effectiveness evidence across countries, primary cost-effectiveness studies should be expanded in all of Africa. This challenge can be addressed partly by training health economists and public health practitioners on the economic evaluation of health interventions in Africa [28].

In the screening step (Fig. 1), we use 'null scenario' as a comparator. The null scenario is a counterfactual 


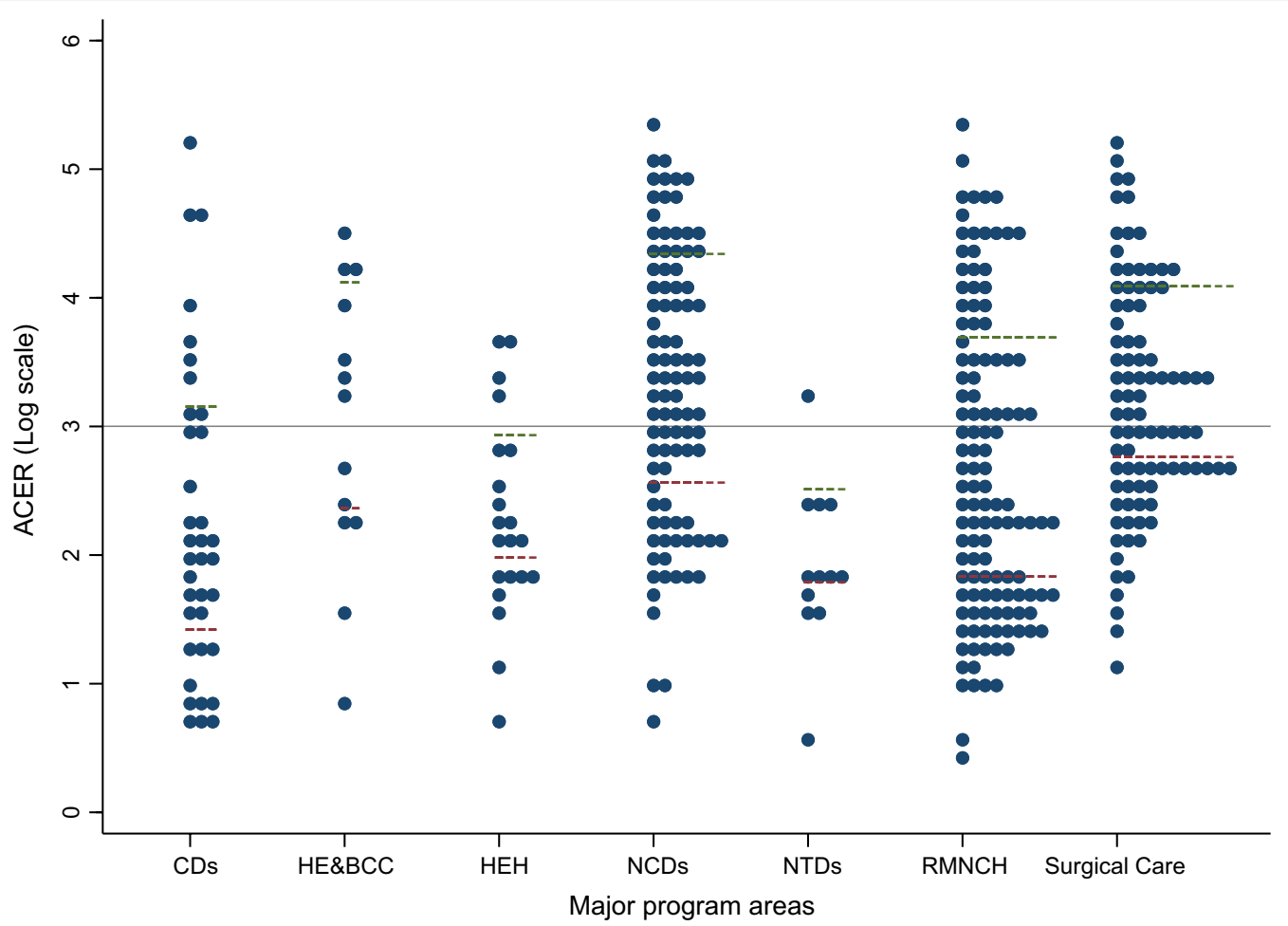

Fig. 2 The ACERs for 382 health interventions by major program area. The Y-axis is ACER in the log scale. The horizontal gray line represents ACER $=$ US\$1000 per DALY/QALY/LYG. A dot represents an ACER for a single intervention

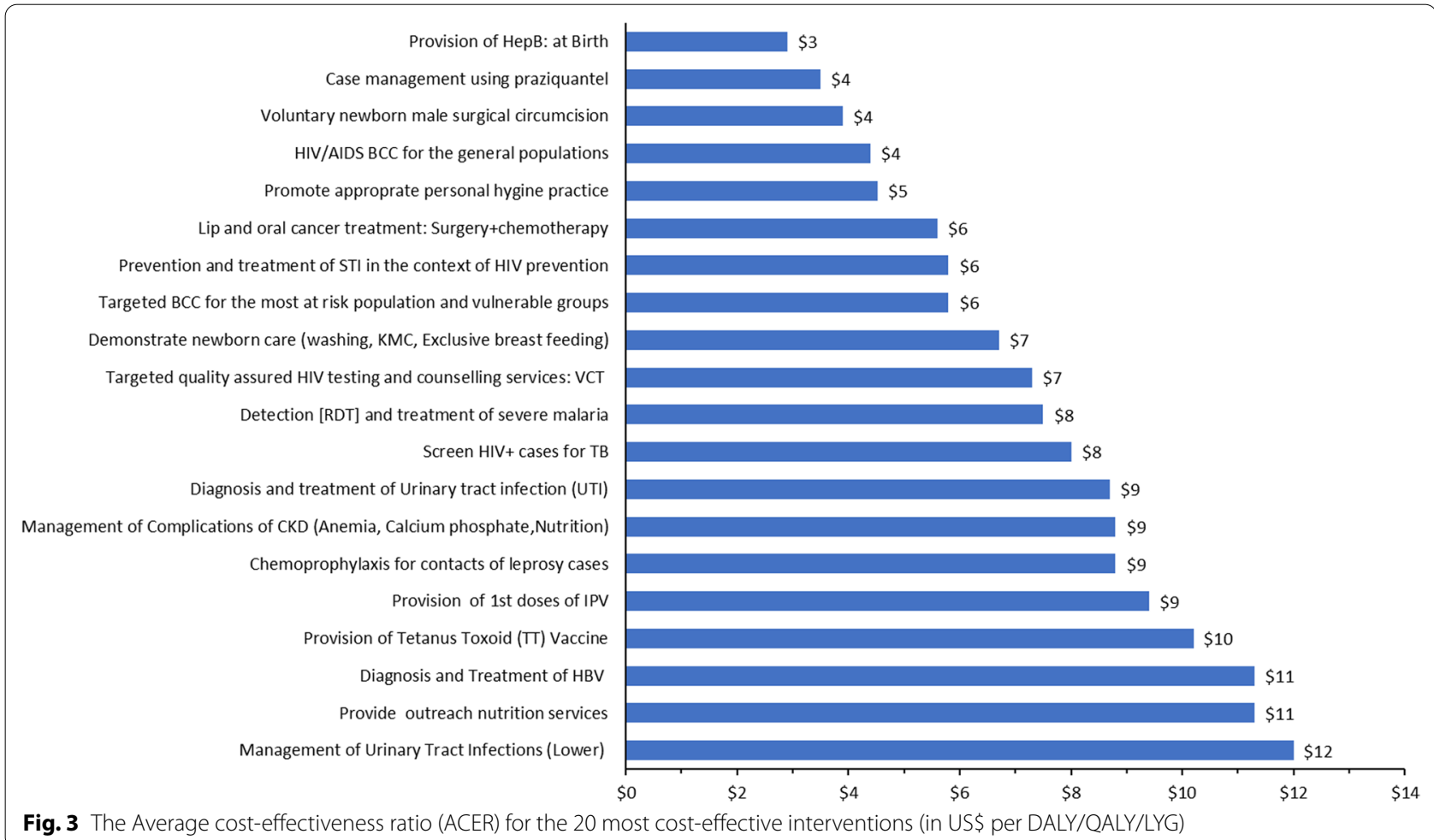




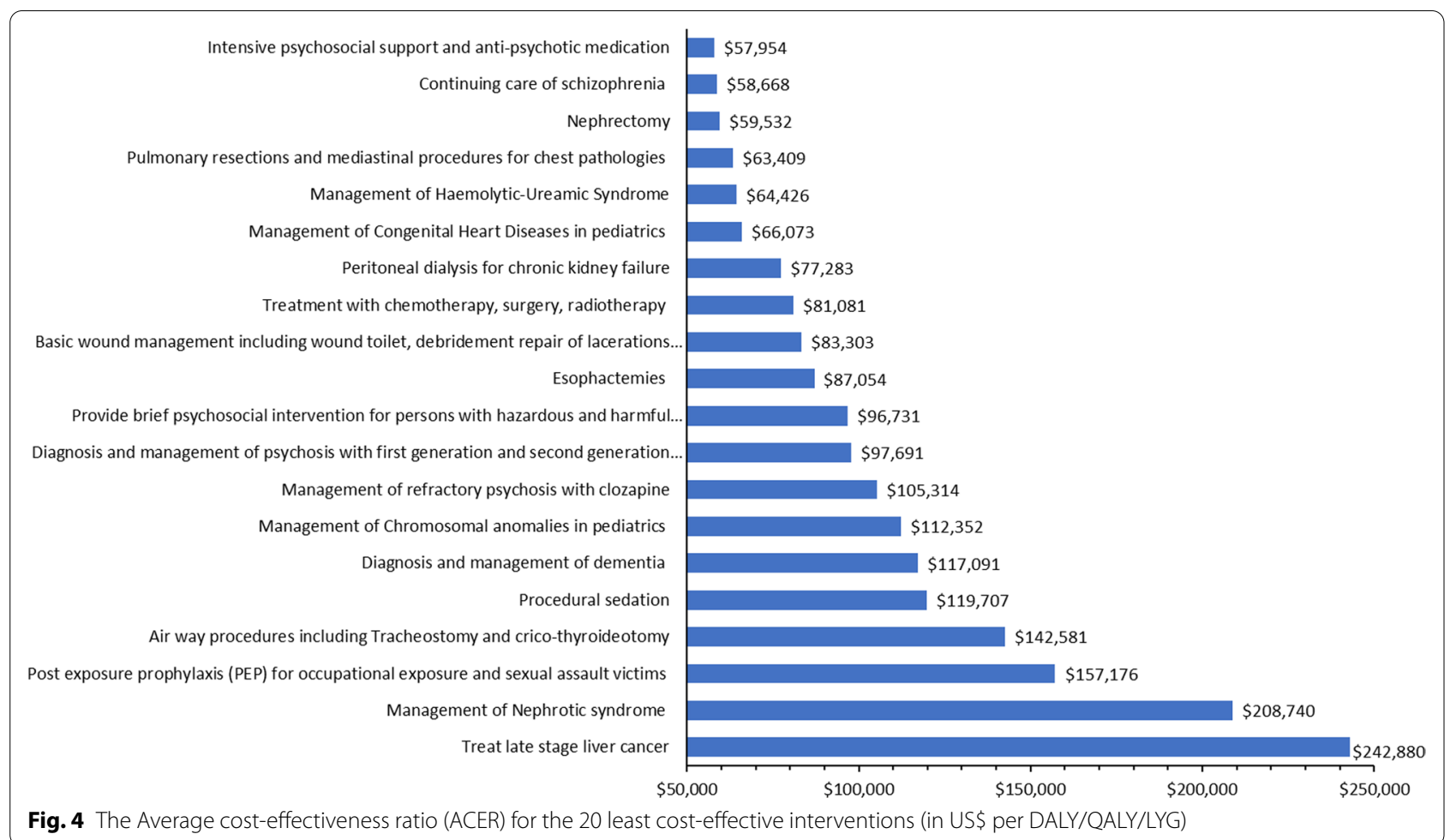

Table 3 Descriptive summary of the average cost- effectiveness ratios (in US\$ per DALY/QALY/LYG) for health interventions by program $(n=382)$

\begin{tabular}{|c|c|c|c|c|c|c|c|}
\hline Program area & Median & p25 & p75 & Min & Max & $N$ & Major program \\
\hline Maternal health & 24 & 19 & 131 & 13 & 21,757 & 8 & $\mathrm{RMNCH}$ \\
\hline NTDs & 65 & 44 & 231 & 4 & 1675 & 12 & NTDs \\
\hline Leprosy & 74 & 32 & 116 & 9 & 138 & 4 & CDs \\
\hline Malaria & 81 & 35 & 609 & 8 & 1185 & 8 & CDs \\
\hline HIV/AIDS & 116 & 7 & 854 & 4 & 157,176 & 15 & CDs \\
\hline $\mathrm{H} \& \mathrm{EH}$ & 116 & 59 & 183 & 5 & 1665 & 17 & H\&EH \\
\hline Eye health problems & 273 & 134 & 687 & 78 & 949 & 6 & NCDs \\
\hline $\mathrm{SRH}$ & 273 & 166 & 2812 & 9 & 52,747 & 26 & $\mathrm{RMNCH}$ \\
\hline Nutrition & 311 & 52 & 1158 & 11 & 56,792 & 35 & $\mathrm{RMNCH}$ \\
\hline Child health & 395 & 32 & 18,696 & 3 & 208,740 & 40 & RMNCH \\
\hline Newborn health & 510 & 92 & 3751 & 4 & 16,460 & 12 & RMNCH \\
\hline Diabetes mellitus & 1005 & 827 & 6356 & 60 & 9450 & 6 & NCDs \\
\hline Surgical care & 1101 & 400 & 5506 & 14 & 142,581 & 82 & Surgical care \\
\hline CVD & 1198 & 122 & 4463 & 46 & 48,729 & 26 & NCDs \\
\hline STI & 1298 & 20 & 9302 & 18 & 49,968 & 9 & CDs \\
\hline Cancer & 1520 & 140 & 20,523 & 6 & 242,880 & 27 & NCDs \\
\hline Health education & 1742 & 167 & 9413 & 7 & 33,763 & 13 & HEBCC \\
\hline CRD & 7564 & 4112 & 20,420 & 164 & 20,533 & 5 & NCDs \\
\hline Anesthesia & 9287 & 1598 & 17,688 & 184 & 119,707 & 8 & Surgical care \\
\hline Renal diseases & 13,930 & 2120 & 55,625 & 9 & 77,283 & 7 & NCDs \\
\hline MNSUD & 20,606 & 1257 & 77,699 & 209 & 117,091 & 16 & NCDs \\
\hline Overall & 677 & 87 & 4761 & 3 & 242,880 & 382 & Overall \\
\hline
\end{tabular}

CVD cardiovascular diseases, CRD chronic respiratory diseases, H\&EH hygiene \& environmental health, MNSUD mental, neurological, \& substance use disorders, SRH sexual and reproductive health, STI sexually transmitted infections, $N$ number of interventions, $p 25$ first quintile, $p 75$ third quintile, min minimum, max maximum 
scenario that assumes none of the interventions existed (i.e., zero cost and zero benefits). Therefore, the use of 'null scenario' as a comparator allows policymakers to broadly compare the ACERs across wide ranges of program areas-within the health sector (i.e., a sector-wide analysis) [29]. Studies that employed "status quo/current practice" as comparators were excluded. Using the status quo or current practice as a comparator implicitly assumes that the current resource use is efficient, while this may not be the case. Comparison of incremental cost-effectiveness ratios (ICERs) using the "current practice" approach is therefore restricted within a group of specific health interventions [8,29-32].

This study has some limitations, and the findings should be interpreted carefully. First, some relevant cost-effectiveness studies might be excluded because of the relatively stringent screening criteria employed in this study. Based on the protocol agreed upon by all the stakeholders for the revision of the Ethiopian EHSP, we included only economic evaluation studies with cost-perDALY, -QALY or -LYG measures [6]. Thus, economic evaluations with the cost-benefit ratio as well as cost per natural unit studies were excluded. However, a bibliometric analysis of published economic evaluation studies by Pitt et. al suggests that cost-utility analyses account for at least half of economic evaluations [33], and other costs per natural unit of measurement may be informative in terms of guiding decisions within a specific program.

Second, the variability in terms of the quality of the studies and transparency in the reporting of cost and health impacts was another challenge to this analysis [26]. Although we employed the Drummond checklist to evaluate the quality of the studies uniformly, there could be some high-quality studies excluded or vice versa. There is some variability in the detailed costing and health benefits measurement approaches. For example, while some of the studies employed a top-down costing, some of the studies were based on ingredients costing. Similarly, while some of the studies used a randomized trial setting to measure intervention benefits, some of them were based on pragmatic clinical or populationbased cross-sectional studies. Furthermore, many of the included studies were from countries and health system contexts substantially different from Ethiopia. Therefore, we recommend that a further detailed examination of individual studies would improve the transferability of the studies $[34,35]$.

Third, this study is not a full systematic review. The ACERs were obtained from the best available individual studies. Further analytic work (e.g., meta-analysis and pooled systematic reviews) on a specific intervention or a group of intervention is needed [36, 37]. Furthermore, we recommend that a formal HTA body should be institutionalized in Ethiopia that can conduct a fullscale assessment of intervention costs and benefits. Costeffectiveness databases should be established in Ethiopia to regularly examine the evidence gap and feed strategic information to the Ministry of Health, Health Insurance Agency, and Ethiopian Pharmaceutical Supply Agency in a timely way.

Fourth, nearly half (48\%) of the studies used in this analysis are from high-income countries settings. Since the context in which the intervention's cost and effectiveness are evaluated varies from the Ethiopian settings, the ACERs also vary. For example, the human resource cost in Ethiopia is relatively low compared with high-income countries in general [38]. Hence, careful consideration should be taken when interpreting the ranking in the league table, and ACERs should be taken only as a general guide in the priority setting process. In addition, a methodological tool is needed that can facilitate the transferability of cost-effectiveness evidence across jurisdictions. There is limited methodological guidance on how to conduct transferability of cost-effectiveness studies across settings $[39,40]$. Most importantly, more costeffectiveness studies should be conducted in Ethiopia, and other low-income settings, using country-level data.

The fifth limitation is that only articles published in the English language were included; we had limited information about cost-effectiveness ratios from articles published in other languages. Additionally, unpublished program evaluation reports were not included in this study, and therefore there may be a publication bias in our data. It is likely that the unpublished reports tend to have more negative findings (i.e., "not cost effective') than published articles [10].

\section{Conclusion}

In conclusion, it is possible to identify relevant economic evaluations using evidence from the literature, even if transferability remains a challenge. The present study identified several cost-effective candidate interventions that could, if scaled up, substantially reduce Ethiopia's disease burden. However, there are gaps in the available evidence on cost effectiveness that can be closed only by conducting more economic evaluation research in developing countries. Therefore, we recommend a concerted effort to establish country-level and a multi-country cost and cost-effectiveness databases in Africa. Furthermore, capacity building through the training of health economists in Africa should be widely undertaken.

\section{Abbreviations}

ACER: Average cost-effectiveness ratios; BCC: Behavioral change communication; CD: Communicable diseases; CEA: Cost-Effectiveness analysis; CMNNDs: 
Communicable, maternal, neonatal, and nutritional diseases; CRD: Chronic respiratory diseases; CVD: Cardiovascular diseases; DALY: Disability-adjusted life year; DCP: Disease control priorities; EHSP: Essential health service package; GDP: Gross domestic product; H\&EH: Hygiene \& environmental health; HTA: Health technology assessment; ICER: Incremental cost-effectiveness ratio; IQR: Interquartile range; LMICs: Low- and middle-income countries; LYG: Life years gained; MNSUD: Mental, neurological, \& substance use disorders; NCD: Noncommunicable diseases; NTDs: Neglected tropical diseases; QALY: Qualityadjusted life year; RMNCH: Reproductive maternal neonatal and child health; SRH: Sexual and reproductive health; STI: Sexually transmitted infections; UHC: Universal health coverage; US\$: United States Dollar; WHO: World Health Organization.

\section{Supplementary Information}

The online version contains supplementary material available at https://doi. org/10.1186/s12962-021-00312-5.

Additional file 1. Example of how evaluation of the studies was done.

Additional file 2. Evaluation of studies.

Additional file 3. ACER for 382 EHSP interventions.

\section{Acknowledgements}

We wish to acknowledge the Federal Ministry of Health of Ethiopia for providing the data for this study. We would also like to thank Stéphane Verguet (Harvard T.H. Chan School of Public Health) and Karin Stenberg (WHO) for providing comments.

\section{Authors' contributions}

$A H, G T E$ and $A Y$ collected the data. AH undertook the data analysis. AH, GTE, $A Y, M Y B, K J$, OFN interpreted the result. AH prepared the first draft manuscript and all authors substantially contribute to writing of this manuscript. All authors contribute by commenting on the draft report. All authors saw and approved the final version and their authorship.

\section{Funding}

The Bill and Melinda Gates Foundation through the Disease Control Priority (DCP)-Ethiopia project (INV-010174) as well as the Trond Mohn Foundation and the Norwegian Agency for Development Cooperation (NORAD) through Bergen Center for Ethics and Priority Setting (BCEPS) have funded this study. The funders had no role in the study design, data collection and analysis, decision to publish, or preparation of the manuscript.

\section{Availability of data and material}

The data sets supporting the conclusions of this article is fully available in the manuscript and additional files.

\section{Declarations}

Ethical approval and consent to participate

The study was approved by the Institutional Review Board of the Ethiopian Public Health Institute (Ref: EPHI/6.13/607).

\section{Consent for publication}

Not applicable.

\section{Competing interests}

The authors have declared that no competing interests exist.

\section{Author details}

${ }^{1}$ Bergen Centre for Ethics and Priority Setting, Department of Global Public Health and Primary Care, University of Bergen, Bergen, Norway. ${ }^{2}$ Ministry of Health of Ethiopia, Addis Ababa, Ethiopia. ${ }^{3}$ Ethiopian Public Health Institute, Addis Ababa, Ethiopia. ${ }^{4}$ Department of Health Systems Governance and Financing, World Health Organization, Geneva, Switzerland. ${ }^{5}$ Department of Global Health and Population, Harvard T.H. Chan School of Public Health, Boston, USA.
Received: 18 November 2020 Accepted: 23 August 2021

Published online: 14 September 2021

\section{References}

1. World Health Report. Financing for universal coverage. Geneva: World Health Organization; 2010.

2. Norheim O, Jha P, Admasu K, Godal T, Hum R, Kruk M, Gómez-Dantés O, Mathers C, Pan H, Sepúlveda J, et al. Avoiding 40\% of the premature deaths in each country, 2010-30: review of national mortality trends to help quantify the UN Sustainable Development Goal for health. Lancet. 2015;385:239-52.

3. Maurice J. UN set to change the world with new development goals. Lancet. 2015;386(September 19):1121-4.

4. Sustainable Development Goals. http://www.un.org/sustainabledeve lopment/health/

5. World Health Organization. Making fair choices on the path to universal health coverage. Geneva: World Health Organization; 2014.

6. Federal Democratic Republic of Ethiopia Ministry of Health. Essential health services package of Ethiopia 2019. Addis Ababa; 2019. https:// www.uib.no/sites/w3.uib.no/files/attachments/essential_health_service_ package_ethiopia_2019_0.pdf.

7. Drummond M. Methods for the economic evaluation of health care programmes. 4th ed. Oxford, New York, NY: Oxford University Press; 2015.

8. Hutubessy R, Chisholm D, Edejer TT. Generalized cost-effectiveness analysis for national-level priority-setting in the health sector. Cost Eff Resour Alloc. 2003;1:8.

9. Ochalek J, Revill P, Manthalu G, McGuire F, Nkhoma D, Rollinger A, Sculpher M, Claxton K. Supporting the development of a health benefits package in Malawi. BMJ Glob Health. 2018;3:e000607.

10. Leelahavarong P, Doungthipsirikul S, Kumluang S, Poonchai A, Kittiratchakool N, Chinnacom D, Suchonwanich N, Tantivess S. Health technology assessment in Thailand: institutionalization and contribution to healthcare decision making: review of literature. Int J Technol Assess Health Care. 2019;35:467-73.

11. Center for the Evaluation of Value and Risk in Health. The cost-effectiveness analysis registry [Internet]. (Boston), Institute for Clinical Research and Health Policy Studies, Tufts Medical Center. www.cearegistry.org Accessed 05 Aug 2020

12. Horton $S$, Gelband H, Jamison D, Levin C, Nugent R, Watkins D. Ranking 93 health interventions for low- and middle-income countries by costeffectiveness. PLoS ONE. 2017;12:e0182951.

13. Hogan DR, Baltussen R, Hayashi C, Lauer JA, Salomon JA. Cost effectiveness analysis of strategies to combat HIV/AIDS in developing countries. BMJ (Clinical research ed). 2005;331:1431-7.

14. Baltussen R, Floyd K, Dye C. Cost effectiveness analysis of strategies for tuberculosis control in developing countries. BMJ. 2005;331:1364.

15. Adam T, Lim SS, Mehta S, Bhutta ZA, Fogstad H, Mathai M, Zupan J, Darmstadt GL. Cost effectiveness analysis of strategies for maternal and neonatal health in developing countries. BMJ. 2005;331:1107.

16. Morel CM, Lauer JA, Evans DB. Cost effectiveness analysis of strategies to combat malaria in developing countries. BMJ. 2005;331:1299.

17. Federal Ministry of Health of Ethiopia. Essential health services package of Ethiopia 2019. Addis Ababa, Ethiopia: Ministry of Health of Ethiopia; 2019.

18. World Health Organization. Global health observatory data repository/ World health statistics; 2018. https://apps.who.int/gho/data/node.main. SDG2016LEX?lang=en.

19. Ethiopia profile. http://www.healthdata.org/ethiopia

20. Ethiopia: GDP per capita, current prices U.S. dollars per capita. https:// www.imf.org/external/datamapper/NGDPDPC@WEO/ETH

21. Federal Ministry of Health of Ethiopia. National health accounts 2016/17. Addis Ababa, Ethiopia: Ministry of Health of Ethiopia; 2019.

22. Eregata GT, Hailu A, Geletu ZA, Memirie ST, Johansson KA, Stenberg K, Bertram MY, Aman A, Norheim OF. Revision of the Ethiopian essential health service package: an explication of the process and methods used. Health Syst Reform. 2020;6:e1829313.

23. Yigezu A, Alemayehu S, Hamusse SD, Ergeta GT, Hailemariam D, Hailu A. Cost-effectiveness of facility-based, stand-alone and mobile-based 
voluntary counseling and testing for HIV in Addis Ababa, Ethiopia. Cost Eff Resour Alloc. 2020;18:34.

24. Drummond MF, Sculpher MJ, Claxton K, Stoddart GL, Torrance GW. Methods for the economic evaluation of health care programmes. Oxford University Press; 2015

25. World Bank. World development indicators: official exchange rate (LCU per US\$, period average). World Bank; 2020.

26. Neumann PJ, Thorat T, Zhong Y, Anderson J, Farquhar M, Salem M, Sandberg E, Saret CJ, Wilkinson C, Cohen JT. A systematic review of cost-effectiveness studies reporting cost-per-DALY averted. PLoS ONE. 2016;11:e0168512.

27. Panzer AD, Emerson JG, $D^{\prime}$ Cruz B, Patel A, Dabak S, Isaranuwatchai W, Teerawattananon Y, Ollendorf DA, Neumann PJ, Kim DD. Growth and capacity for cost-effectiveness analysis in Africa. Health Econ. 2020;29:945-54.

28. Tichenor M. Essential universal health coverage needs local capacity development. Lancet Glob Health. 2020;8:e748-9.

29. Baltussen R, Brouwer W, Niessen L. Cost-effectiveness analysis for priority setting in health: penny-wise but pound-foolish. Int J Technol Assess Health Care. 2005:21:532-4.

30. Murray CJ, Evans DB, Acharya A, Baltussen RM. Development of WHO guidelines on generalized cost-effectiveness analysis. Health Econ. 2000;9:235-51.

31. Bertram MY, Lauer JA, Stenberg K, Edejer TTT. Methods for the economic evaluation of health care interventions for priority setting in the health system: an update from WHO CHOICE. Int J Health Policy Manag 2021.

32. Eregata GT, Hailu A, Stenberg K, Johansson KA, Norheim OF, Bertram MY. Generalised cost-effectiveness analysis of 159 health interventions for the Ethiopian essential health service package. Cost Eff Resour Alloc. 2021;19:2.

33. Pitt C, Goodman C, Hanson K. Economic evaluation in global perspective: a bibliometric analysis of the recent literature. Health Econ. 2016;25(Suppl 1):9-28.

34. Briggs A. Transportability of comparative effectiveness and cost-effectiveness between countries. Value Health. 2010;13:S22-5.

35. Drummond M, Barbieri M, Cook J, Glick HA, Lis J, Malik F, Reed SD, Rutten F, Sculpher M, Severens J. Transferability of economic evaluations across jurisdictions: ISPOR good research practices task force report. Value Health. 2009;12:409-18.

36. van Mastrigt GAPG, Hiligsmann M, Arts JJC, Broos PH, Kleijnen J, Evers SMAA, Majoie MHJM. How to prepare a systematic review of economic evaluations for informing evidence-based healthcare decisions: a fivestep approach (part 1/3). Expert Rev Pharmacoecon Outcomes Res. 2016;16:689-704.

37. Wijnen BFM, Van Mastrigt GAPG, Redekop WK, Majoie HJM, De Kinderen RJA, Evers SMAA. How to prepare a systematic review of economic evaluations for informing evidence-based healthcare decisions: data extraction, risk of bias, and transferability (part 3/3). Expert Rev Pharmacoecon Outcomes Res. 2016;16:723-32.

38. Agarwal A, Mann C, Abdella E, Mitiku W, Alebachew A, Berman P. Recurrent costs in primary health care in Ethiopia: facility and disease specific unit costs and their components in government primary hospitals and health centers. BMC Health Serv Res. 2020;20:389.

39. Arnold M, Griffin S, Ochalek J, Revill P, Walker S. A one stop shop for cost-effectiveness evidence? Recommendations for improving Disease Control Priorities. Cost Eff Resour Alloc. 2019;17:7.

40. Kim DD, Bacon RL, Neumann PJ, Culyer A. Assessing the transferability of economic evaluations: a decision framework. Non-communicable disease prevention: best buys, wasted buys and contestable buys. Open Book Publishers; 2019. p. 91-117.

\section{Publisher's Note}

Springer Nature remains neutral with regard to jurisdictional claims in published maps and institutional affiliations.
Ready to submit your research? Choose BMC and benefit from:

- fast, convenient online submission

- thorough peer review by experienced researchers in your field

- rapid publication on acceptance

- support for research data, including large and complex data types

- gold Open Access which fosters wider collaboration and increased citations

- maximum visibility for your research: over $100 \mathrm{M}$ website views per year

At BMC, research is always in progress.

Learn more biomedcentral.com/submissions 